through a No. 3 ocular layer inverted on the side, as taught by Stoehr in his practical book of histology, they give a fair idea of what the deposits looked like, which I saw on the back of the cornea. With the slit-lamp and high power and the judicious use of illuminations they were seen easily, as was also their tinge of buff.

I am indebted to Mr. Valentine for kindly furnishing me with what notes and sketches he possessed of this case while the man was under his care. He first came to him on August 13, 1926, one week after the accident. The iris was prolapsed, vision on August 20 was fingers. On August 21 the prolapse was excised and the hole covered with conjunctiva, fastened with two stitches. The lower lid was cauterized in six places on its conjunctival surface for ectropion.

No one desires more than I do that the true credit in this case be given to the true cause. My scepticism of the value of therapeutic remedies in this disease inclines me to attribute it so entirely to surgery, that in a similar case I would feel like eliminating them, were it not for the blood condition, which has been put clearly before us. ${ }^{(3)}$ In the face of such convincing evidence one does not feel justified in suspending the additional therapeutic measures. But admitted we must combat them : are these blood conditions pathognomonic of sympathetic ophthalmitis? I shall not feel they are, until similar blood changes have been positively excluded in all other forms of uveitis. And this is a point for investigation for those who are in a position to carry it out.

\title{
REFERENCES
}

1. Hepburn, Malcolm.-Trans. Ophthal. Soc. U.K., Vol.XLVI, p. 244. par. 4.

2. Butler, T. Harrison.-Trans. Ophthal. Soc. U.K., Vol. XLVI, p. 261.

3. Browning, S. H.-Trans. Ophthal. Soc. U.K., Vol. XLVI, p. 249.

\section{A NEW OPERATING LOUPE}

BY

\section{Priestley Smith}

BIRMINGHAM

Magnification is a decided advantage in such minute work as eye-surgery. The best means is a pair of lenses placed at a considerable distance from the wearer's eyes, for to obtain the desired magnification by glasses worn close to the eyes the lenses have to be so strong that one is compelled to get too close to the field of operation. For the best result they must be not much less than $8 \mathrm{~cm}$. from the wearer's cornea.

Another advantage of having them at such a distance from the eyes is that by using lenses of the right size one can magnify 
just so much of the field of view as is needed, leaving room to look above, below, and to either side of the lenses, at things further off-including the instrument tray--which would be blurred if looked at through them.

On the other hand, the lenses must not be too far from one's eves : if they are more than about $10 \mathrm{~cm}$. the view of the operation

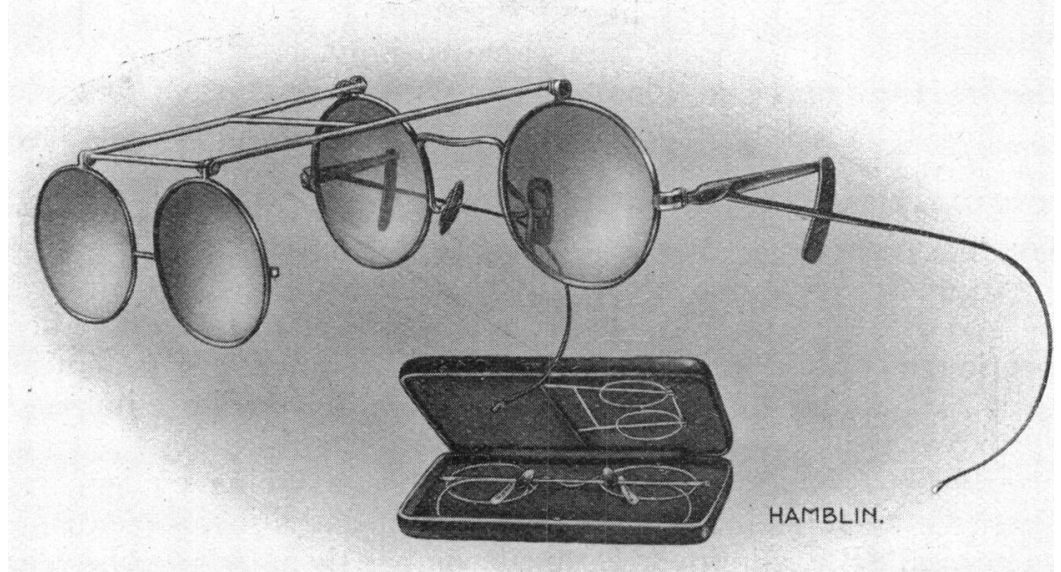

area seen through them moves about too much with every movement of the wearer's head.

In the present instrument these magnifying lenses are carried on a light rigid scaffold springing from the tops of the rims of a pair of spectacles worn in the ordinary position. These spectacles are glazed with the surgeon's own distance correction, if his error of refraction is great enough to impair definition to a material extent. In my own case I find it worth while to correct half a dioptre of astigmatism.

By a simple device, the invention of the makers, at the sides of the spectacles, their slant, together. with that of the object lenses, can be varied at will by the wearer.

The object lenses can be folded flat against their carrier, which latter is instantly detachable from the spectacle frame, so that the whole instrument folds into a conveniently small case.

The strength of the lenses (including prisms), and the placing of the glasses are designed to obtain the necessary magnification (not quite 1.5 diams.) at a comfortable working distance, and with the least possible disturbance of muscle-balance. I have used the experimental models for two years, and find the instrument most helpful.

The instrument is made by Messrs. Theodore Hamblin, Itd. 